\title{
Detection and analysis of pharmaceutical products from the waste water system at the university teaching hospital of Yaoundé, Cameroon
}

\begin{abstract}
Human pharmaceutical residues are fast becoming an environmental concern. Their occurrence has been reported in many countries especially in Europe and America. They have been reported to have eco-, geno- and human toxic effects and thus their importance as micro pollutants cannot be ignored. However, African countries are still lagging behind in research concerning these micro pollutants. In view of this fact, the present study was to investigate the presence of pharmaceutical residues in waste waters of the University Hospital Centre of Yaoundé (UHCY). Based on the consumption of drugs in UHC during 2014, we selected the most representative ones that are known to be common in the waste water. Then we collected 1L sample of CHUY waste water in order to screen the pharmaceuticals. The screening was carried out using 2 methods: High Performance Liquid Chromatography coupled to a Triple Quadruple analyzer (LC/QQQ) and High Performance coupled to a Mass Spectrometer, with a Time of Flight analyzer (LC/Q-TOF). The two methods was used to identify and quantify 19 pharmaceuticals. The concentrations found varied from 0,088 for clarithromycineto $211,926 \mu \mathrm{g} / \mathrm{L}$ for paracetamol. These results confirmed the presence of such residues in our environment and hence emphasized the need to establish modern waste water treatment devices at CHUY and for all the Reference hospitals in Cameroon. The study also elucidated the need to integrate pharmaceutical waste management into the strategic development plan of the Ministry of Public Health.
\end{abstract}

Keywords: pharmaceuticals, environment, UHCY, waste water, LC/QQQ, LC/QTOF
Volume 4 Issue 6 - 2018

\author{
Vanessa Edwigetchadji,' Evrad Martial \\ Nguidjoe,' Estella Tembe-Fokunang,' \\ Kathleenngu, ${ }^{2}$ Charles Ntungwen Fokunang \\ 'Department of Pharmacotoxicology \& Pharmacokinetics, \\ University of Yaoundé I, Cameroon \\ ${ }^{2}$ University Teaching Hospital Center, Yaoundé, Cameroon
}

\begin{abstract}
Correspondence: Estella Tembe-Fokunang, Department of Pharmacotoxicology \& Pharmacokinetics, Faculty of Medicine and Biomedical Sciences, University of Yaoundé I, Cameroon, Tel +237670902446, Email charlesfakunang@yahoo.co.uk
\end{abstract}

Received: October 27, 2018 | Published: November 26, 2018

\section{Introduction}

In the last decade, the use of pharmaceuticals has grown worldwide, leading to their presence in the environment. In fact, medical care waste increases due to the rise in number and shape of medical services, centers and the increasing importance of pharmaceutical use. ${ }^{1}$ Pharmaceuticals are biologically active substances specially designed to act on living things (humans and animals) and because of that, the potential exists for unexpected impacts at low concentrations. They are disposed or discharged into the environment through a variety of sources. These include: human activities, pharmaceutical industries, illicit drug use, agribusinesses, veterinary drugs and hospitals. ${ }^{2}$ Many studies have reported the presence of pharmaceuticals in various water samples including hospital waste waters ${ }^{1,3}$ in countries like Italy, Spain, USA, Germany and even Nigeria. As at the time of this research, no data is available in Cameroon.

Pharmaceutical Waste must be disposed of as hazardous waste Many chemical and/or pharmaceutical compounds used in research or in the treatment of disease at the University of Florida are regulated by the EPA as listed or characteristic hazardous wastes when disposed. ${ }^{4}$

The Resource Conservation and Recovery Act (RCRA) regulations establish basic hazardous waste management standards for persons who produce hazardous waste, called hazardous waste generators. These standards are found in title 40 of the Code of Federal Regulations (CFR) in part 262. The generator regulations ensure that hazardous waste is appropriately identified and handled safely to protect human health and the environment, while minimizing interference with daily business operations. ${ }^{2,5}$
This study aimed at screening the possible presence of pharmaceuticals in hospital waste waters from the University Hospital Centre of Yaoundé, a reference hospital in Cameroon. The pharmaceuticals were selected because of their high usage rate in the hospitals in 2014 and were investigated to detect their possible presence in water samples.

\section{Materials and method}

This study was an observational descriptive and analytic study, conducted at the University Hospital Centre of Yaoundé (UHCY)

During the duration of six months and the selection of pharmaceutical to analyze was based according to a survey carried out in the hospital ${ }^{4}$ on the most consumed drugs in 2014 and considering the standards available in the laboratory.

\section{Sample Collection and preparation}

The sample was collected on the $11^{\text {th }}$ of May 2015 in an amber bottle of $1 \mathrm{~L}$ and filtered through a net in order to reduce solid compounds in the sample.

The analysis of the sample was done at the Civil engineering, environmental and architectural for mass spectrometry at the University of Colorado.

According to International Air Transporters Association (IATA) procedures, ${ }^{5}$ the sample was classified category B and therefore needed a triple packing to ship. The packing was constituted of: A primary, secondary and a tertiary in which a list of information 
concerning the sample was put and on which the addresses and the names of receptors were written.

\section{Analysis}

Waste water sample was analyzed through the methods developed by Ferrer et al..$^{6,7}$ Analysis were done through a HPLC coupled to a mass spectrometer in tandem with triple quadruple analyzer and a HPLC coupled to mass spectrometer in tandem with time of flight analyzer.

\section{Results}

\section{Survey of most consumed drug at CHU}

The drugs were classified according to their DCI (International Common Denomination) and according to their therapeutic classes. One hundred and seventy sixteen (176) active ingredients and 23 therapeutics classes constituted the list of drugs consumed within the hospital. After this classification, the quantities consumed for each of them by service have been determined. From these quantities, the percentages of each class in the consumption and in each service were calculated. The percentage of each active ingredient per family was then calculated. The Table 1 below shows the drugs detected, the method used and the concentrations found. Finally, propranolol, trimetoprime, sulfamethoxazole and clarithromycine were detected respectively at $298 \mathrm{ng} / \mathrm{L}, 265 \mathrm{ng} / \mathrm{L}, 162 \mathrm{ng} / \mathrm{L}, 88 \mathrm{ng} / \mathrm{L}$. Figure 1 is a summary of drugs detected.

\section{The percentages of consumption of each therapeutic class during 2014 at the $\mathrm{CHU}$}

This study targeted 40 drugs but only 19 were detectable. The concentrations of detected drugs vary from 88 to $211926 \mathrm{ng} / \mathrm{L}$. These results have the exception of one or two, higher than those obtained during other research studies on hospital waste waters. LC/QQQ permitted to identify 10 molecules and LC/Q-TOF 9 molecules. Paracetamol was the most important one with a concentration of 211926ng/L following by metformin (154000ng/L), ibuprofene, O-demethyl tramadol (141000ng/L), tramadol (76000ng/L), cimetidine (34000ng/L), ciprofloxacine $(24000 \mathrm{ng} / \mathrm{L})$, sucralose $(13073 \mathrm{ng} / \mathrm{L})$ and erythromycin anhydrate $(7000 \mathrm{ng} / \mathrm{L})$. Caffeine, hydroxyl omeprazole, carbamazepine, atenolol, azithromycine and diphenhydramine were found respectively at $5800 \mathrm{ng} / \mathrm{L}, 5000 \mathrm{ng} / \mathrm{L}$, 940ng/L, 427ng/L, 390ng/L and 377ng/L.

Table I Drugs detected, the methods used and the concentrations found

\begin{tabular}{|c|c|c|c|}
\hline Therapeutic classes & Drugs & Detection method & Concentration $(\mathrm{ng} / \mathrm{L})$ \\
\hline \multirow{4}{*}{ Analgesics and anti-infla } & Paracetamol & LC/QQQ & 211926 \\
\hline & Ibuprofen & LC/Q-TOF & 141000 \\
\hline & Tramadol & LC/Q-TOF & 76000 \\
\hline & O-demethyltramadol & LC/Q-TOF & 141000 \\
\hline \multirow{6}{*}{ Antibiotics } & Erythromycinanhydrate & LC/Q-TOF & 7000 \\
\hline & Ciprofloxacine & LC/Q-TOF & 24000 \\
\hline & Clarithromycine & LC/QQQ & 88 \\
\hline & Azitromycine & LC/Q-TOF & 390 \\
\hline & Sulfamethoxazole & LC/QQQ & 162 \\
\hline & Trimetoprime & LC/QQQ & 265 \\
\hline Excitants & Caffeine & LC/QQQ & 5800 \\
\hline Antiepileptics & Carbamaeépine & LC/QQQ & 940 \\
\hline \multirow{2}{*}{ Antihypertensives } & Atenolol & LC/QQQ & 427 \\
\hline & Propranolol & LC/QQQ & 298 \\
\hline \multirow{2}{*}{ Antiacides } & Cimetidine & LC/Q-TOF & 34000 \\
\hline & Hydroxy omeprazole & LC/Q-TOF & 5000 \\
\hline Anti histaminics & Diphenhyramine & LC/QQQ & 377 \\
\hline Antidiabétics & Metformine & LC/Q-TOF & 154000 \\
\hline Edulcorant & Sucralose & LC/QQQ & 13073 \\
\hline
\end{tabular}




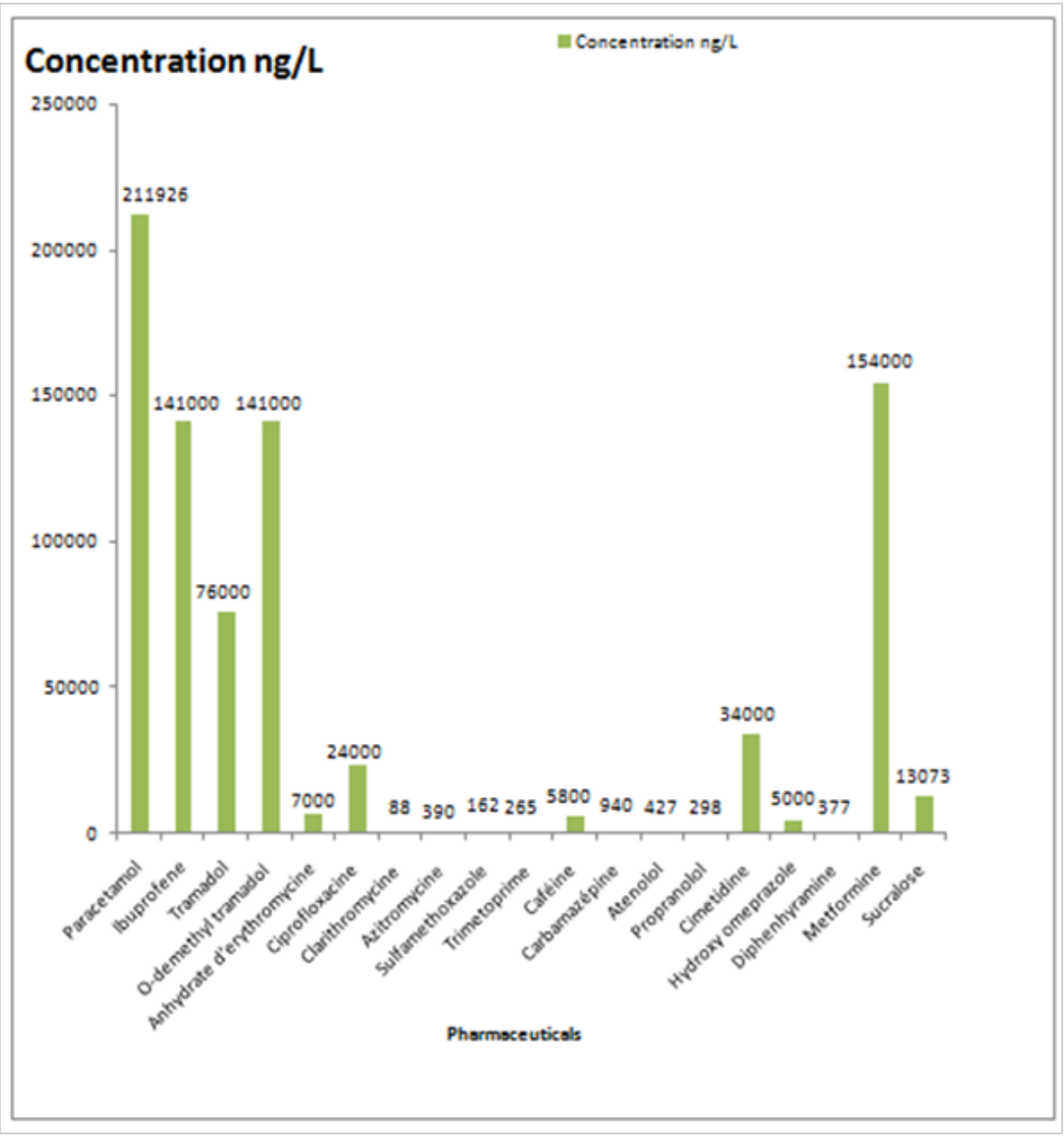

Figure I Concentrations (ng/L) of drugs detected in YUHC waste water.

\section{Discussion}

Analgesic represented the $5^{\text {th }}$ class of the most consumed drugs in YHUC in $2014^{4}$ so the probability to detect them was high. Paracétamol was the most abundant with a concentration of $211926 \mathrm{ng} / \mathrm{L}$. This tends to confirm its high rate of use in the YUHC as proven by a survey where it emerged as the most consumed in the analgesics family. This tendency of use is also found in many studies proving that analgesics are one of the most consumed drugs in the world., ${ }^{3,-14}$ The paracetamol concentration found in this study was higher than those reported in the literature. ${ }^{8-14}$ However in 2 studies $^{15,16}$ in Norway in 2006 and 2007, there was a concentration of 329852ng/L, higher than the one found $(211926 \mathrm{ng} / \mathrm{L})$ in YUHC. On another hand, Sim et al., ${ }^{17}$ couldn't detect paracetamol in 4 Korean hospitals. These differences could be attributed to differences between the patients and the type of analgesics used. The great capacity of paracetamol binding on solid materials, especially stools in this case, which limits its hydrolysis and therefore its degradation, would be another justification of the high concentration found. ${ }^{18}$ Ibuprofen is an anti inflammatory drug generally used in ambulatory treatment. Packer and al in 2003 demonstrate that only $15 \%$ of ibuprofen is excreted unchanged. ${ }^{13}$
Thinking of this information and the percentage of consumption in UHCY $(0,05 \%)$, the value of $141000 \mathrm{ng} / \mathrm{L}$ seems to be high. May be its current use by UHCY or the use of waste waters as a means of elimination of drugs can explain that value. Petrovic et al., ${ }^{17}$ and Waed et al., ${ }^{3}$ found ibuprofen at the concentrations of 370ng/L to 27900ng/ $\mathrm{L}^{19}$ and $26 \mu \mathrm{g} / \mathrm{L}^{1}$ less than the one found in $\mathrm{UHCY}$ waste water.

Tramadol is an opiod antalgic. During its metabolism, it is demethyled and becomes 0 -dimethyl tramadol ${ }^{20}$ it was then normal to find the 2 compounds in the sample analyzed. However the concentration of O-diméthyl tramadol (141000ng/L) was 1,7 higher than the parent compound $(76000 \mathrm{ng} / \mathrm{L})$ probably because of its high metabolism. Gomez and Puttmann in $2012^{20}$ found tramadol and o-demethyl tramadol respectively at concentrations of $757 \mathrm{ng} / \mathrm{L}$ and $122 \mathrm{ng} / \mathrm{L}^{20}$ in waste water lesser to ours.

Sucralose is an edulcorant widely used in sweet things and sugar of diabetic. Even if it was not identified as one of the compounds used in hospital, it could be the result of the metabolism of food consumed by patients, hospital employees and nurses at the hospital. The concentration of caffeine found $(5800 \mathrm{ng} / \mathrm{L})$ could be due to its daily 
consumption in fluids like coffee, coca cola, tea by the employees, the patients and the nurses patients of the hospital. Some authors also found caffeine at concentrations lesser or higher than the one of UHCY in hospital waste water where drugs made of caffeine are not used. ${ }^{3,8,13,14}$

In spite of their low consumption in the hospital $(0,368 \%),{ }^{4}$ anti epileptics as carbamazepine have been detected at a concentration of $940 \mathrm{ng} / \mathrm{L}$. This could be explained by the fact that antiepileptic treatment was long life on the contrary to other drugs whose consumption was occasional. Another reason could be the persistence of carbamazepine in liquid compartments leading to its bioaccumulation. ${ }^{3,21}$ The concentration found was superior to the one found by Almeida et al., ${ }^{22}$ at $461-588 \mathrm{ng} / \mathrm{L}$ in waste water of a psychiatric hospital in Brazil. ${ }^{22}$ This result (940ng/L) was nevertheless similar to the ones found during a study on hospital water in Portugal by Santos et al., ${ }^{21}$ with concentrations varying from 450 and $1050 \mathrm{ng} / \mathrm{L}^{23}$ and by Verlicchi et al., ${ }^{20}$ with concentrations varying from 640 to $1200 \mathrm{ng} / \mathrm{L} .{ }^{21}$

Antihypertensives were the $3^{\text {rd }}$ therapeutic class consumed in UHCY in 2014; that was why we emitted the hypothesis to find them UHCY waste water. The presence of atenolol and propranolol was therefore not surprising even if these two were not the most consumed in this therapeutic class. One of the reasons could be the use of atenolol and propranolol in ambulatory treatment which led to a constant of these in water if we suppose that personnel of UHCY and external people were potential consumers. In Cameroon 15 people on 100 have hypertension. ${ }^{24}$ Zhou in 2008 found propranolol at concentrations varying from 100 to $1090 \mathrm{ng} / \mathrm{L}^{25}$ in waste water of a hospital in the UK on the way to STEP including value of this study (298ng/L). Similar concentrations were also found in studies made by Almeida et al. ${ }^{22}$ and Mendoza et al. en $2015^{26}$ varying respectively from 100 to $1090 \mathrm{ng} / \mathrm{L}^{22}$ and $101-573 \mathrm{ng} / \mathrm{L} .{ }^{26}$ Concerning atenolol, Santos et al., ${ }^{23}$ found it at concentrations of 8,55 to $8037 \mathrm{ng} / \mathrm{L}$ including the result obtained in this study $(427 \mathrm{ng} / \mathrm{L})$. Contrary to Mendoza et al., ${ }^{22}$ who found it at concentrations varying from $626-2320 \mathrm{ng} / \mathrm{L}^{26}$ superior to the concentration of this study.

Antibiotics were the most consumed class of drugs and were part of substances with high probability to be found in water and their detection therefore confirmed our statement.

Sample analysis showed the presence of sulfamethoxazole and trimetoprime. These two drugs are commercialized on the name of cotrimoxazole in the ratio (trimetoprime/sulfamethoxazole) 1:5 even if the concentrations do not reflect this proportion. The concentration of sulfaméthoxazole $(162 \mathrm{ng} / \mathrm{L})$ was similar to the one obtained by Kovalova et al., ${ }^{15}$ Thomas et al., ${ }^{21}$ and Verlicchi et al., ${ }^{27}$ Santos et al found trimetoprime at concentratrations ranging of 30,5 to $1182 \mathrm{ng} / \mathrm{L}$ in a general hospital and from 12,5 to $1089 \mathrm{ng} / \mathrm{L}^{23}$ in a pediatric hospital; similar to the concentration found in this study $(265 \mathrm{ng} / \mathrm{L})$.

Concerning clarithromycin, Mendoza et al in 2015 found it at concentrations ranging from 78 to $498 \mathrm{ng} / \mathrm{L}^{26}$ in a Spanish hospital; including the one found in UHCY sample $(88 \mathrm{ng} / \mathrm{L})$. Others studies found it in waste water samples at concentrations lower than the one found in UHCY waste water. ${ }^{3,8-12}$

Fluoroquinolones (FQ) is a sub class of antibiotics in which levofloxacine and ciprofloxacine are found. They have been reported to be poorly biodegradable. ${ }^{3}$ It is thus not surprising to find it in waste waters of health centers using it; but only ciprofloxacine has been able to be detected and identified in sample. Based on the drug consumption in UHCY, ${ }^{4}$ levofloxacine was the most consumed of FQ $(4,039 \%)$ followed by ciprofloxacine and ofloxacine at $0.03 \%$. This finding invalidates part of our statement according to which the most consumed drugs are susceptible to be found in waste water. Lindberg et al in 2007, Thomas et al en 2007 and Verlicchi et al., ${ }^{20}$ found ciprofloxaxine at concentrations varying from 3600-101000ng/ $\mathrm{L}_{,}{ }^{28} 23336 \mathrm{ng} / \mathrm{L}^{15}$ and $1400-26000 \mathrm{ng} / \mathrm{L}^{21}$ respectively similar to ours (24000ng/L). Same thing for Kovalova in 2012 and Santos in 2013 which found it at concentrations taken to $31980 \mathrm{ng} / \mathrm{L}^{27}$ for the 1 st and $38689 \mathrm{ngL}^{23}$ for the $2^{\text {nd }}$.

Erythromycin and azithromycin are part of macrolides, antibiotics which inhibit bacteria protein's synthesis. Halling-Sorensen et al in 1998 demonstrated that erythromycin became erythromycin anhydrate in solutions at $\mathrm{pH}$ less than $7 .{ }^{10}$ It is not surprising to only detect its derivative because the sample $\mathrm{pH}$ was adjusted to this value to permit the filtration his derivative. This value is therefore a proof of the presence of erythromycin in the sample at the beginning of the analysis. Santos found it at concentrations varying from 47,8 to $7545 \mathrm{ng} / \mathrm{L}^{23}$ in a maternity and azithromycin at concentrations varying from 89,2 to $4492 \mathrm{ng} / \mathrm{L} .{ }^{23}$ These concentrations are similar to ones found in our study $24000 \mathrm{ng} / \mathrm{L}$ for l'érythromycine and 390ng/L pour l'azithromycine.

Belonging to the class of antihistaminics, diphenhydramin is a molecule very present in antitussives and flu drugs. It is not present in the list of the most consumed drugs in UHCY but its presence in the sample may be due to the fact that the sampling was done during a flu episode.

Artemether, artésunate and oméprazole even if they were the most consumed in UHCY were not detected. One reason could be their degradation in water or their high metabolism in the body. Therefore it would useful to research their metabolites or their degradation products. An omeprazole metabolite was detected although the value was estimated not ascertained due to the lack of analytical standard.

Metformine is an oral anti diabetic drug. Its high use is a consequence of diabetes being the 2 nd cause of morbidity in Cameroon. ${ }^{24}$ In spite of its low consumption during 2014 in UHCY $(0,013 \%)$, metformin was found in the analyzed sample at a concentration of $154 \mu \mathrm{g} / \mathrm{L}$. One of the reasons of its detection could be the metabolism of metformin. In fact, it is not metabolized in the body and it is found unchanged in stools and urines..$^{10}$ Another reason could be linked to the epidemiologic profile of Cameroon where 9 people on 100 have diabetes including hospital workers and nurses ${ }^{24}$ and metformin is the most used drug to treat it. The concentration found is similar to the one found by Trautwein et al in 2014 in waste water going inside a STEP $(86,2 \text { à } 142,3 \mathrm{ng} / \mathrm{L})^{29}$ and higher than those generally found in the literacy. ${ }^{3,8,23}$

\section{Conclusion}

A sample of UHCY was used for the determination of drugs or their metabolites. The analysis was done through the methods developed by Irma et al., ${ }^{6}$ Ferrer et al., ${ }^{7}$ using a HPLC coupled to a mass spectrometer in tandem with a triple quadripole and a HPLC coupled to a mass spectrometer in tandem with a time of flight analyzer. At the end 19 molecules (drugs and degradation products) 
were detected on the 40 choose. The concentrations found varied from 88 to $211926 \mathrm{ng} / \mathrm{L}$. Paracetamol was the drug detected at the highest concentration $(211926 \mathrm{ng} / \mathrm{L})$ followed by metformin with a concentration of $154000 \mathrm{ng} / \mathrm{L}$. The compounds found belonged to 5 major classes (antibiotics, analgesics/ anti-inflammatory, antacids, antihypertensives and anti diabetics). The class of antibiotics was the most represented with 6 compounds detected (clarithromycine, azithromycine, sulfamethoxazole, trimethoprime, erythromycine, ciprofloxacine). Relatively understudied, these medicines may have a non environmental risk if we consider the quantities brought to aquatic compartment and on the other hand the fact that they are designed to be biologically active. These results could be the basis for an environmental risk evaluation of UHCY and other hospitals' waste waters in Cameroon.

\section{Acknowledgments}

None.

\section{Conflict of interest}

The author declares no conflict of interest.

\section{References}

1. WaedAlahmad R, Mahmoud Alawi A. HPLC/UV/Fluorescence detection of several pharmaceuticals in Hospital Effluents Using HPLC with UV and Fluorescence Detectors. Journal of Pharmaceutical Sciences. 2012;5:22-29.

2. US-EPA. Pharmaceuticals and personal Care products as pollutants Science Inventory. 2004.

3. Zuccato E, Castiglioni S, Bagnati R, et al. Source, occurrence and fate of antibiotics in the Italian aquatic environment. $J$ Hazard Mater. 2010;179(1-3):1042-1048.

4. TchadjiMayoudom Vanessa Edwige. Présence des résidus de médicaments dans les eaux uses du Centre Hospitalier et Universitaire de Yaoundé. Doctorat en Pharmacie. Faculté de Médecine et de Sciences Biomédicales: Université de Yaoundé I; 2015. 150 p.

5. NC State University, US Department of transportation \& International Air transports association. Guide to Shipping Biological Materials. 11 p.

6. Ferrer Irma, Zweigenbaum Jerry A, Thurman Michael E. Analysis of 70 Environmental Protection Agency priority pharmaceuticals in water by EPA Method 1694. J Chromatogr A. 2010;1217(36):5674-5686.

7. Ferrer I, Thurman E. Analysis of 100 pharmaceuticals and their degradates in water samples by liquid chromatography/quadrupole time-of-flight mass spectrometry. Journal of Chromatography A. 2012;1259:148-157.

8. Gros M, Petrović M, Barceló D. Development of a multi-residue analytical methodology based on liquid chromatography-tandem mass spectrometry (LC-MS/MS) for screening and trace level determination of pharmaceuticals in surface and wastewaters. Talanta. 2006;70(4):678690.

9. Hignite C, Azarnoff D. Drugs and drug metabolites as environmental contaminants: Chlorophenoxyisobutyrate and salicylic acid in sewage water effluent. Life Sci. 1977;20(2):337-341.

10. Halling-sorensen B, Nors Nielsen S, Lanzky PF, et al. Occurrence, fate and effects of pharmaceutical substances in the environment - A review. Chemosphere.1998;36(2):357-393.

11. Sumpter J P, Johnson AC. Lessons from endocrine disruption and their application to other issues concerning trace organics in the aquatic environment. Environ Sci Technol. 2005;39(12):4321-4332.
12. Glassmeyer ST, Kolpin DW, Furlong ET, et al. Environmental Presence and Persistence of Pharmaceuticals: An Overview. Fate of Pharmaceuticals in the Environment and in Water Treatment Systems. Boca Raton, CRC Press; 2008. p. 3-51.

13. Packer JL, Werner JJ, Latch DE, et al. Photochemical fate of pharmaceuticals in the environment: naproxen, diclofenac, clofibric acid, and ibuprofen. Aquatic science. 2003;65(4):342-351.

14. Jones OA, Lester JN, Voulvoulis N. Pharmaceuticals:a threat to drinking water? Trends Biotechnol. 2005;23(4):163-167.

15. Langford KH, Thomas KV. Determination of pharmaceutical compounds in hospital effluents and their contribution to wastewater treatment works. Environ Int. 2009;35(5):766-770.

16. Kummerer K, Helmers E, Hubner P, et al. European hospitals as a source for platinum in the environment in comparison with other sources. $S c i$ Total Environ. 1999;225(1-2):155-165.

17. Zhou JL, Zhang ZL, Banks E, et al. Pharmaceutical residues in waste water treatment works effluents and their impact on receiving river water. J Hazard Mater. 2008;166(2-3):655-661.

18. Bui Van Hoi. Contribution à l'étude de la présence et du devenir des résidus de médicaments dans les compartiments aquatiques. Doctorat en chimie analytique et environnement. Ecole Doctorale des Sciences Chimiques: Université de Bordeaux 1; 2013. p. 235.

19. Farre M, Petrovic M, Barcelo D. Recently developed GC/MS and LC/MS methods for determining NSAIDs in water samples. Anal Bioanal Chem. 2007;387(4):1203-1214.

20. Verlicchi P,Al Aukidy M, Galletti A, et al. Hospital effluent: Investigation of the concentrations and distribution of pharmaceuticals and environmental risk assessment. Sci Total Environ. 2012a;430:109-118.

21. Almeida CAA, Brenner Carla GB, MinettoLuciane, et al. Determination of pharmaceuticals, antianxiety and antiepileptics drugs in hospital effluent and a preliminary risk assessment. Chemosphere. 2013;93:2349-2355.

22. Mendoza A, Aceña J, Pérez S, et al. Pharmaceuticals and iodinated contrast media in a hospital waste- water:A case study to analyse their presence and characterize their environmental risk and hazard. Environmental Research. 2015;140:225-241.

23. Larsson DGJ, et al. Is heart rate in fish a sensitive indicator to evaluate acute effects of $\beta$-blockers in surface water? Environmental Toxicology and Pharmacology. 2006;22(3):338-340.

24. Rua-Gomez PC, Puttmann W. Impact of waste water treatment plant discharge of lidocaine, tramadol, venlafaxine and their metabolites on the quality of surface waters and ground water. $J$ Environ Monit. 2012;14(5):1391-1399.

25. Chang X, Meyer MT, Liu X, et al. Determination of antibiotics in sewage treatement plant and source of Gorge reservoir Pollution. Environ Pollut. 2010;158(5):1444-1450.

26. TrautweinChristoph, Berset Jean-Daniel, WolschkeHendrick. et al. Occurrence of the antidiabetic drug Metformin and its ultimate transformation product Guanylurea in several compartments of the aquatic cycle. Environ Int. 2014;70:203-212.

27. Snyder LR, Kirkland JJ. Introduction to modern liquid chromatography. New York: Wiley; 1979. p. 500.

28. Jean J. Identification et priorisation des substances médicamenteuses bioaccumulables rejetées dans les effluents hospitaliers. Th. D: Diplome d'études spécialisées de pharmacie hospitalière et des collectivités. ENTPE: Lyon; 2008. 154 p.

29. Guilcarpi Duran CI. Fact sheets Physical and Chemical Characteristics: CVEN 9855- water and waste water analysis and quality requirements. 2013. p. 8 . 